\title{
Illicit Drug Use by Adolescents: A Public Perception of Influencing Factors in Owerri, Nigeria
}

Udochukwu Ugochukwu Ogu ( $\square$ udo2ogu@gmail.com )

University of Nigeria Teaching Hospital https://orcid.org/0000-0002-4643-5160

Nkoli Ezumah

University of Nigeria - Enugu Campus

Aloysius Odii

University of Nigeria

\section{Research}

Keywords: Public perception, illicit drug, influential factors, adolescent, Nigeria

Posted Date: October 12th, 2020

DOl: https://doi.org/10.21203/rs.3.rs-38029/v2

License: (a) (1) This work is licensed under a Creative Commons Attribution 4.0 International License. Read Full License 


\section{Abstract}

Background: Illicit drug use among adolescents has become a public health concern which cuts across all social strata. This study explored the public perception of factors that influence illicit drug use among adolescents in Owerri, Nigeria.

Methods: A descriptive cross-sectional research design was used for the study. The study adopted a mixed-method approach comprising quantitative and qualitative methods and was carried out in Owerri metropolis of Imo State, Nigeria. The research instruments used for data collection were questionnaires and in-depth interview guide. The target population comprised adults 18 years and above residing in the area of interest at the time of the study. For the qualitative method, a total of 10 communities were selected randomly by balloting and availability sampling was employed in the selection of respondents. Respondents for the qualitative method were purposively selected.

Results: Our quantitative study found that $50.7 \%$ of the respondents, from across the three areas in Owerri metropolis, asserted that peer influence, emotional problems, relationship problems, wanting to feel 'high' are factors influencing adolescent consumption of illicit drugs whereas the qualitative study found family background, unique experience such as the death of a loved one, affliction or misfortune as factors influencing adolescents' illicit drug use. The quantitative results showed that persons with a higher level of education are more likely than those with a lower level of education to perceive a significant difference in drug use between in - school and out - of - school adolescents.

Conclusions: Peer influence, emotional problems, relationship problems, the influence of media (especially the social media), among several other identified reasons are perceived by the public as factors that influence adolescents' use of illicit drugs. As a means to curb some of these factors, the communities, schools and universities should formulate contextual policies policies to prevent drug use and should also hold seminars for parents and families to alert them early to the symptoms of drug use in their children.

\section{Background}

Recent trends indicate that the use of drugs have dramatically increased worldwide (1-4). It has been estimated that (in 2011) between $3.6 \%$ and $6.9 \%$ of persons aged 15 to 64 years across the globe have used an illicit drug in the preceding year (5). World Health Organization (6) reported that every year, about 320, 000 young people between ages of 15 and 29 years die annually from alcohol and drug use, i.e., $9 \%$ of all the deaths in that age category and 15.3 million persons have drug use disorders. The global disease burden attributable to illicit drugs is estimated at $5.4 \%$ (7).

Illicit drugs use (such as heroin, marijuana, etc.) particularly by adolescents, globally has been a public concern $(8,9)$. This is due to the potential short and long-term adverse effects or consequences associated with their use on the wellbeing of those who use drugs and the larger society (9). For instance, the use of marijuana by adolescents has been associated with an increased risk of a range of negative health outcomes, including future depression, anxiety disorders $(10,11)$, fatal automobile collisions $(10,12)$, accidental injuries, chronic bronchitis, and respiratory infections $(10,13)$.

Across the globe, there have been pointers to factors that influence adolescents' involvement in drug use. Some of the factors listed as reasons for adolescent involvement in illicit drug use are peer pressure, friends-do-it, sexual prowess, curiosity, boldness, enhanced spirit performance, social influence, psychological stress, pleasure, and inadequate knowledge of the harmful consequences etc. (14-17). Ndu, Ndu, Olarewaju and Somoye (18) added lack of selfconfidence, search for excitement, experimentation and conduct problems. 
In Nigeria, the majority of persons who use illicit drugs start at adolescence, as they tend to follow a particular pattern of involvement with drugs (19). Studies show that adolescents in Nigeria start using drugs as early as 10 years old (19-23). In a study by Adelekan and Ndom (22), the respondents reported using cannabis (marijuana) and cigarettes on a daily and weekly basis. A good number of adolescents ignorantly depend on one form of drug or the other for various daily activities-social, educational, political, moral etc. (24). These drugs include Tobacco, Indian hemp, Cocaine, Morphine, Heroine, Ephedrine, Madras, Caffeine, Glue, Barbiturates, and Amphetamines (24).

Youths from diverse socio-cultural backgrounds have been known to use drugs (25), and this includes those from both rich and poor backgrounds. A study by Ibebuike (26) sought to determine the rate of substance used, and adverse effects amongst senior secondary school students of Eziachi, Orlu, Imo state. The study found that the majority of them used substances due to peer pressure, while for others it is due to academic adjustment, social and psychological factors. The most common reasons given for substance use was to have a feeling of belonging, followed by "to increase morale" and to have pleasure, to be awake because it is cheap and is always available. Other systems currently available to gauge drug use levels and trends, such as the national household survey of drug use estimating the drug use in the total population have not been performed in Imo State till date (27).

Recently, researchers have started paying attention to the issue of illicit drug use in Nigeria $(14,15,23,28)$. However, most of these studies ignored the public perception of illicit drug use among youths. Considering that the public has an important role to play in an attempt to reduce the rate of illicit drug use, how they perceive illicit drug use among youths must be ascertained. Moreover, how the public perceives an issue may reveal the level of attention it gets and the best strategies of addressing it. Because perception is shaped by things such as past experience, cultural expectations, motivations, moods, needs and attitudes $(29,30)$, ignoring it on issues that require modifying public policy or public behaviour, may result in the failure of technically good innovations. It is against this backdrop that this study focuses on exploring the public perception of factors influencing illicit drug use among adolescents in Owerri metropolis.

\section{Research Objective}

- To ascertain the factors that influence adolescent drug use from the perspective of the public.

\section{Research Questions}

1. 1. What are the factors that influence illicit drug use among adolescents?

2. Would adolescents still consume illicit drugs if they knew the possible consequences?

3. Is there a difference in drug use between in-school adolescents and out-of-school adolescents?

\section{Hypotheses}

1. There is no significant difference in the proportion of males and females who will perceive that adolescents would consume illicit drugs even if they knew the possible consequences.

2. There is a significant difference in the educational level of respondents who will perceive a significant difference in drug use between in - school and out - of - school adolescents. 


\section{Theoretical framework}

Social Learning Theory (by Albert Bandura in 1977) was adopted for this study. Social Learning Theory holds that behaviour is influenced by environmental factors, not just psychological or cognitive factors. Thus, Social Learning Theory assumes that behavioural, psychological and environmental factors combined, influence the development of specific behaviours. In other words, what people are exposed to or observe could make all the difference in their lives. Using this theory, this study ascertained the extent to which a person's behavioural intentions can be affected by what he/she expects to experience and how much these expectations stand to cover the person's ability to see its damaging effects. The theory is also relevant in exploring the role of the public (as an aspect of the environmental factor) towards these expectations and possible outcome i.e. what the public is exposed to (in terms of knowledge on adolescent drug us). Sex and educational level are characteristics that could affect the public's perception on the subject matter.

\section{Methods}

Study design and study area

A descriptive cross-sectional research design was used for the study. The study adopted a mixed method approach comprising quantitative and qualitative methods. The area of study was Imo state, and there are 27 local government areas in Imo state. However, only three that make up Owerri metropolis were used for the study. The three local government areas that make up Owerri metropolis include Owerri West, Owerri North and Owerri Municipal. The choice of this study area arose from the fact that there are undocumented reports of illicit drug use among young people in the region.

\section{Study population and selection of study participants}

The study population consisted of members of the public aged 18 years and above, residing in Owerri metropolis at the time of the study. The projected (from the 2006 Nigerian Population Census) figures show that 403,425 people reside in Owerri metropolis. Specifically, Owerri North constitute 176,334; Owerri west constitute 101,754 while Owerrimunicipal constituted 125,337.

To ensure that Owerri metropolis' urban and rural communities and their respondents were truly represented in the population, a cluster sampling procedure was adopted. The justification for this is because Owerri metropolis has a considerable land mass and it will be difficult and expensive to cover such vast area. The 40 communities that comprise Owerri metropolis were represented with numbers and these numbers written on individual pieces of paper, folded and shuffled (selection by balloting). They were selected one after the other randomly until the desired figure was reached. The same procedure was repeated for the three local governments. A total of 10 communities were selected randomly in all: four communities from the 16 communities that make up Owerri West, five communities from the 18 communities that make up Owerri North and one community from the five communities that make up Owerri Municipal. Simple random sampling technique of balloting without replacement was used to determine which communities get picked from the LGAs. Using Taro Yamane formula for determining finite population, 0.04 was used as the degree of error expected, the sample size derived for the study was 624 . In the four communities that were selected from Owerri West, 200 respondents were randomly selected. In the five communities that were selected from Owerri North, 220 respondents were randomly selected. In the one community that was selected from Owerri Municipal, 204 respondents were randomly selected. Information was collected from students living in off campus hostels, people in offices, markets and people found on the street all of whom meet the age category for the study. The lead author trained 2 researchers who participated in data collection.. 
The research instruments used for data collection were questionnaires and in-depth interview guide. The questionnaire contained semi-structured questions. The questionnaire was developed based on the objective of the study. The questionnaire elicited information on the respondents' perception of factors influencing adolescents' involvement in illicit drug use, and consequences of these factors as well as strategies to curb illicit drug use among adolescents. The questionnaires were distributed to respondents in their homes, on the street at their places of employment. The distribution was based on the availability of the respondents and they must meet the study criteria to.

The interview guide contained structured questions on adolescent drug use, factors influencing their involvement as well strategies to curb them. A total of 16 respondents were purposively selected for key Informant interviews (KIls) which were in-depth in nature. Three respondents from a Psychiatric unit at Owerri (a representative of office of the director [RepOD], a doctor and a nurse), by virtue of their profession as medical and health personnel, the researchers believe that they would be well informed of the issue under investigation. A representative of the social welfare, at Owerri [RepSW], was also selected because it was believed that he would possess knowledge about deviant behaviours of young people in the metropolis. These 4 respondents were interviewed in their respective offices. Also, twelve other respondents (four from each LGA) comprising of an elder statesman and woman, youth leaders and other influential community leaders were selected for the in-depth interview. Among these $12 \mathrm{KII}$ respondents, 9 were interviewed at their homes while 3 were interviewed in a bar of their own choosing. The rationale for their selection was based on the assumption that they are knowledgeable about the subject matter and how it plays out in their respective communities.

\section{Validity and reliability test of the instrument}

The face validation of the instrument was determined by subjecting the instrument to the scrutiny of experts in the field of Sociology from the Sociology/Anthropology of the University of Nigeria, Nsukka. They experts were allowed free hand. The modifications and suggestions made by the experts were incorporated to produce the final copy of the instruments. A pilot study was conducted with 62 (10\% of the study sample size) respondents chosen randomly from Okigwe LGA. This area has similar characteristics as the study area in terms of population and structure. The responses were coded and put into the computer using SPSS v21.

\section{Data analysis}

The data from questionnaires were collated and coded manually and entries put into the computer. The data was analyzed with the Statistical Package for Social Sciences (SPSS version 21). The analysis employed descriptive statistics such as frequencies and percentages to present the characteristics of the research subjects. Chi-Square $\left(\chi^{2}\right)$ (goodness of fit and test of independence) was used to ascertain the differences among male and female respondents regarding their perception on whether adolescents would consume illicit drugs if they knew the possible consequences; and whether there is a significant difference in the educational level of respondents who will perceive a significant difference in drug use between in - school and out - of - school adolescents. The hypothesis will also, offer further explanation to objectives 2 and 3.. In analyzing the qualitative data, the researcher began with careful transcription of the data. The transcripts derived from the in-depth interviews were read and coded with the Nvivo 11 software according to emerging themes. Thematic methods were used in the analysis of the qualitative data. The emerging themes were further grouped into major recurring themes and then analyzed accordingly. Salient illustrative quotes were then pulled out to complement and elucidate the quantitative data in reporting the results.

\section{Results}




\section{Results}

Out of the total of 624 questionnaires that were distributed in the course of the study, 535 questionnaires were properly filled and returned - showing a response rate of $85.7 \%$. Specifically, 209 questionnaires were returned from respondents in Owerri North, 221 and 105 questionnaires in Owerri West and Municipal respectively.

\section{Socio-Demographic data of the Respondents}

Table 1 highlights the distribution of respondents according to their sex, age, educational attainment, marital status and occupation. 


\begin{tabular}{|c|c|c|c|}
\hline \multicolumn{4}{|c|}{ Socio-demographics } \\
\hline Sex & No of Respondents & Percentage (\%) & \\
\hline Male & 255 & 47.7 & \\
\hline Female & 280 & 52.3 & \\
\hline Total & 535 & 100 & \\
\hline Age of respondents & Male (\%) & Female (\%) & Total (\%) \\
\hline $18-27$ years & $110(43.1)$ & $93(33.2)$ & 203(37.9) \\
\hline $28-37$ years & $33(12.9)$ & $101(36.1)$ & $134(25.0)$ \\
\hline $38-47$ years & $60(23.6)$ & $42(15.0)$ & $102(19.2)$ \\
\hline $48-57$ years & $48(18.8)$ & $41(14.6)$ & $89(16.6)$ \\
\hline 58 years and above & $4(1.6)$ & $3(1.1)$ & $7(1.3)$ \\
\hline Total & $255(100)$ & $280(100)$ & $535(100)$ \\
\hline Educational attainment & Male (\%) & Female (\%) & \\
\hline No formal education & $12(4.7)$ & $44(15.7)$ & $56(10.5)$ \\
\hline Primary school & $22(8.6)$ & 47 (16.8) & $69(12.9)$ \\
\hline Secondary school & $29(11.4)$ & $92(32.9)$ & $121(22.6)$ \\
\hline N.C.E* & $42(16.5)$ & $18(6.4)$ & $60(11.2)$ \\
\hline OND/HND** & $50(19.6)$ & $38(13.5)$ & $88(16.5)$ \\
\hline B.Sc./B.Tech. & $80(31.4)$ & $40(14.3)$ & $120(22.4)$ \\
\hline Other (specify) & $20(7.8)$ & $1(0.4)$ & $21(3.9)$ \\
\hline Total & $255(100)$ & $280(100)$ & $535(100)$ \\
\hline Marital status & Male (\%) & Female (\%) & \\
\hline Married & $64(25.1)$ & $127(45.4)$ & 191(35.7) \\
\hline Widowed & $0(0)$ & $23(8.2)$ & $23(4.3)$ \\
\hline Divorced & $9(3.5)$ & $10(3.6)$ & $19(3.6)$ \\
\hline Separated & $19(7.5)$ & $32(11.4)$ & $51(9.5)$ \\
\hline Single & 163(63.9) & $88(31.4)$ & $251(46.9)$ \\
\hline Total & $255(100)$ & $280(100)$ & $535(100)$ \\
\hline Occupation & Male (\%) & Female (\%) & \\
\hline Unemployed & $23(9.0)$ & $42(15.0)$ & $65(12.1)$ \\
\hline Trading & $77(30.2)$ & $122(43.6)$ & 199(37.2) \\
\hline
\end{tabular}

Page 7/17 


\begin{tabular}{|l|l|l|l|} 
Business & $145(56.9)$ & $88(31.4)$ & 233(43.6) \\
\hline Civil service & $4(1.5)$ & $26(9.3)$ & $30(5.6)$ \\
\hline Other (specify ) & $6(2.4)$ & $2(0.7)$ & $8(1.5)$ \\
\hline Total & $255(100)$ & $280(100)$ & $535(100)$ \\
\hline
\end{tabular}

1. *N.C.E. - National Certificate Examination ** OND- Ordinary National Diploma **Higher National Diploma

Source: (Illicit drug use study 2018)

\section{Factors influencing adolescents' involvement in illicit drug use}

The information in Table 2 shows a multi-choice response of factors that respondents believe influence adolescents' use of illicit drugs. Majority of the respondents (92.9\%) chose peer influence. Other factors chosen are to feel 'high' (70.5\%) and Emotional problems (67.8\%), amongst others.

Table 2 Factors influencing illicit drug use among adolescents

\begin{tabular}{|l|l|}
\hline What are the factors that influence illicit drug use among adolescents? (multiple choice response) & $\begin{array}{l}\text { Frequency (\%) } \\
\mathrm{N}=535\end{array}$ \\
\hline Peer influence & $497(92.9)$ \\
\hline Emotional problems & $363(67.8)$ \\
\hline To feel 'high' & $377(70.5)$ \\
\hline Relationship problems & $79(14.8)$ \\
\hline Others (to before better in competitions like sports and debates and to assimilate better and easier what they read) & 91 (17) \\
\hline
\end{tabular}

Source: Survey (2018) for Illicit Drug paper

\section{If adolescents would consume illicit drugs if they knew the possible consequences}

Respondents views were sought on whether or not adolescents would consume illicit drugs (e.g., cocaine, weed, etc) if they knew the possible consequences. According to the data in Table 3, over half (58.3\%) of the entire respondents disagreed that adolescents would consume illicit drugs (e.g., cocaine, weed, etc) if they knew the possible consequences; $34.6 \%$ agreed, while $7.1 \%$ indicated that they did not know the likely outcome.

Table 3: Would adolescents consume illicit drugs (e.g., cocaine, weed, etc.) if they knew their consequences 


\begin{tabular}{lr}
\hline Yes & $185(34.6)$ \\
No & $312(58.3)$ \\
\hline Don't know & $38(7.1)$ \\
\hline Total & $535(100)$ \\
\hline
\end{tabular}

Source: Survey (2018) for Illicit Drug paper

The information in Table 4 shows a sex disaggregated distribution of respondents on reasons adolescents would consume illicit drugs (e.g., cocaine, weed, etc) if they knew their possible consequences. The result shows that $42.2 \%$ of the entire study respondents believed that because it is difficult to change habitual compulsive behaviours, adolescents would continue to use illicit drugs even if they knew about the possible consequences,

Table 4: Reasons why adolescents would use illicit drugs (e.g., cocaine, weed, etc) if they knew their consequences

\begin{tabular}{l}
\hline Reasons adolescents would consume illicit drugs despite knowledge of their effect \\
\hline Peer group influence \\
Social comparisons \\
Belief that consequences are over exaggerated
\end{tabular}

\begin{tabular}{lr} 
Youthful exuberance & $4(2.2)$ \\
Total & $185(100)$ \\
\hline
\end{tabular}

Source: Survey (2018) for Illicit Drug paper

Respondents were asked to state whether there is a difference in drug use between adolescents who are in school and those who are not. In line with this, table 5 shows that $51.4 \%$ stated that there is a difference in drug use between inschool and out-of-school adolescents. On the contrary, $37.4 \%$ of the respondents said there is no difference. However, $11.2 \%$ of the respondents did not know whether a difference exists. 
Table 5: Is there a difference in drug use between in-school adolescents and out-of-school adolescents

\begin{tabular}{ll}
\hline Difference? & Frequency (\%) \\
\hline Yes & $275(51.4)$ \\
No & $200(37.4)$ \\
\hline Don't know & $60(11.2)$ \\
\hline Total & $535(100)$ \\
\hline
\end{tabular}

Source: Survey (2018) for Illicit Drug paper

Hypotheses testing

Hypothesis 1: There is a significant difference in the proportion of males and females who will perceive that adolescents would consume illicit drugs even if they knew the possible consequences.

$\mathrm{H}_{1}$ : There is a significant difference in the proportion of males and females who will perceive that adolescents would consume illicit drugs even if they knew the possible consequences.

$\mathrm{H}_{0}$ : There is no significant difference in the proportion of males and females who will perceive that adolescents would consume illicit drugs even if they knew the possible consequences.

This hypothesis was tested using analyzed data in Tables 1 and 3 . While data in Table 1 contains respondents' information on sex, Table 3 contained information on the perception of respondents on whether adolescents would consume illicit drugs if they knew the possible consequences. Furthermore, respondents' information in Table 3 was recoded and categorized into two independent categories; with respondents who said 'don't know' being excluded from the categories and thus the analysis. In order to test this hypothesis, a chi-square $\left(X^{2}\right)$ test of independence and the statistical package (SPSS 21.0) were employed. However, a cross tabulation of the independent variable (respondents' sex) and the dependent variable (respondents' perception on whether adolescents would consume illicit drugs if they knew the possible consequences) were computed and presented in Table 6:

Table 6: Respondents' sex and perception on whether adolescents would consume illicit drugs if they knew the possible consequences

\begin{tabular}{l|lcc}
\hline Respondents' & \multicolumn{1}{l}{ Adolescents would consume illicit drugs if they knew the possible consequences } & Total \\
sex & Yes (\%) & No (\%) & 244(49.1) \\
Male & $112(60.5)$ & $132(42.3)$ & $253(50.9)$ \\
Female & $73(39.5)$ & $180(57.7)$ & $497(100)$ \\
Total & $185(100)$ & $312(100)$ & \\
\hline
\end{tabular}

Source: Survey (2018) for Illicit Drug paper 
From Table 6, it could be observed that of all the respondents who said that adolescents would consume illicit drugs even if they knew the possible consequences, majority were males (60.5\%) and the remaining $39.5 \%$ were females. On the other hand, more than half of the respondents who disagreed with this statement were females while the remaining $42.3 \%$ were males. This output suggests that there were more female than male respondents who did not think that adolescents would consume illicit drugs if they knew the possible consequences.

A further observation of the chi-square output shows a statistically significant difference in the proportion of male and female respondents regarding their perception of whether adolescents would still consume illicit drugs even if they knew the consequences $\left(X^{2}=15.5 ; \mathrm{df}=1, \mathrm{~N}=497, \mathrm{P}<.001\right)$. In other words, the $X^{2}$ value of 15.5 indicates a remarkable difference between the observed proportional differences and what is expected by chance occurrence. In order to ensure that no assumptions were violated, appropriate steps were taken, and it was established that the calculated $X^{2}$ value at 15.5 is greater than the tabulated value $X^{2}$ value at 10.828. As a result, the substantive hypothesis that: "There is a significant difference in the proportion of males and females who will perceive that adolescents would consume illicit drugs even if they knew the possible consequences." is upheld.

Hypothesis 2: There is a significant difference in the educational level of respondents who will perceive a significant difference in drug use between in - school and out - of - school adolescents.

$\mathrm{H}_{1}$ : There is a significant difference in the educational level of respondents who will perceive a significant difference in drug use between in - school and out - of - school adolescents.

$\mathrm{H}_{0}$ : There is no significant difference in the educational level of respondents who will perceive a significant difference in drug use between in - school and out - of - school adolescents.

The hypothesis was tested using analyzed data in Tables 1 and 5. While the data in Table 5 contains respondents' information on whether there is a difference in drug use between adolescents who are in school and those who are not (e.g., dropouts), the data in Table 1 containing information on respondents educational levels (amongst others) were re-categorized with respondents with no formal education, primary school and secondary school classified as belonging to a lower educational level (246 in all) and respondents in the other categories as those with a higher level of education (289 in all). Here, respondents' information in Table 5 were re-coded and categorized into two independent categories; with respondents who said 'don't know' being excluded from the analysis. Here, only 475 respondents' information were used for testing the hypothesis. In order to test this hypothesis, a chi-square $\left(X^{2}\right)$ test of independence and the statistical package (SPSS 21.0) were employed. This response is reflected in Table 7.

Table 7: Respondents' educational levels and their perception on whether there is a difference in drug use between adolescents who are in school and those who are not

\begin{tabular}{l|lcc}
\hline Respondents' & \multicolumn{2}{l}{ perception of drug use between adolescents who are in school and those who are not } & Total \\
Educational Levels & & No (\%) & $275(57.9)$ \\
\hline High & $175(71.4)$ & $100(43.5)$ & $200(42.1)$ \\
Low & $70(28.6)$ & $130(56.5)$ & $475(100)$ \\
Total & $245(100)$ & $230(100)$ & \\
\hline
\end{tabular}


From Table 7, it could be observed that of all the study respondents who perceived a difference between adolescents who are in school and those who are not as regards their drug use, a greater majority $(71.4 \%)$ were in the category of those with higher educational level, while the remaining $28.6 \%$ were in the category of those with lower educational level. On the other hand, majority of the respondents (56.5\%) who perceived that there is no difference between adolescents who are in school and those who are not as regards their drug use were in the category of those with higher educational level, while the remaining $43.5 \%$ were in the category of those with lower educational level. Overall, more respondents with higher level of education than those with a lower level of education perceived a difference between adolescents who are in school and those who are not as regards their drug use. A further observation of the chi-square output shows a statistically significant difference in the proportion of respondents with higher level of education and those with a lower level perceived a difference between adolescents who are in school and those who are not as regards their drug use $\left(X^{2}=36.9 ; \mathrm{df}=1, \mathrm{~N}=497, \mathrm{P}<.001\right)$. In other words, the $X^{2}$ value of 15.5 indicates a remarkable difference between the observed proportional differences and what is expected by chance occurrence. In order to ensure that no assumptions were violated, appropriate steps were taken, and it was established that the calculated $X^{2}$ value at 36.9 is greater than the tabulated value $X^{2}$ value at 10.828 . As a result, the substantive hypothesis that: "There is a significant difference in the educational level of respondents who will perceive a significant difference in drug use between in - school and out - of - school adolescents." is upheld.

\section{Qualitative findings}

\section{Reasons adolescents use illicit drugs}

For the qualitative findings, reacting to this, respondents mentioned such factors as peer pressure, family background, emotional problems, major life events or unique experience (death of a loved one, affliction or misfortune), youthful exuberance, the need to feel 'high', mass media, personality factors, among others. Respondents were also asked to discuss the ways in which these factors impact on adolescents' choice of illicit drug use and behaviour. One of the respondents who described how emotional problems impact adolescents' choice of illicit drug use and behaviour had this to say:

"... someone may feel that the economic realities are so harsh and thus insolvent and may experience depression. Depending on his/her ability to cope with the situation, such a person may take to illicit drugs as a temporary measure to forget about his/her environment" (RepOD).

Another respondent who spoke extensively on how major life events or unique experience (death of a loved one, affliction or misfortune) can influence adolescents' illicit drug use opined that "...some experience can cause a dramatic change in a persons' life to an extent that taking to drugs become the only escape route. For instance, a rape or incest victim may constantly take to drugs whenever she thinks of the horrific experience she had":

Will adolescents use drugs if they knew the possible consequences?

Majority respondents averred that the knowledge of the consequences of drug intake cannot necessarily decrease its usage. To them, the instant gratification and the euphoria that come with drug use may encourage adolescents to rationalize illicit drug use. One of the respondents puts it this way: 
"Because adolescents perceive issues relating to the implications of illicit drugs on human lives as an abstract subject, they tend to justify the existence of drugs. Some of the adolescents go as far as arguing that illicit drug use is as old as man and because a pocket of people die due to drug use, does not mean that it will kill everyone. One of the younger folks I counseled at a time, told me that drug kills people who are not smart at taking it. The implication is this: it is either the usage increases or stays the same way" (Nurse).

Other respondents who perceived that the knowledge of the consequences of illicit drugs can influence adolescents to decrease their drug intake expressed the view that adolescents may find it very difficult to actually stop; however, they can decide to stop or reduce the intake if they are faced with pernicious situations. Bolstering this position, one of the respondents averred that: "the crisis that comes with addiction and the whole withdrawal symptoms thing can make the knowledge of the consequences of illicit drugs meaningless" (Youth leader, male).

\section{Discussion}

The study examined the perception of the public on factors influencing illicit drug use among adolescents. Knowing the perception of the public would help inform future steps that might be taken towards ameliorating this public health concern. From the findings, majority of the respondents considered peer influence as a leading factor influencing illicit drug use. . Other factors are the desire to feel 'high', emotional problems, relationship problems and to cope with their academic problems or assimilate better, what they read. They also indicated that some of these adolescents use illicit drugs to help them cope with challenges such as harsh economic realities or the death of a loved one which could create a vacuum in their heart, or traumatizing circumstances like rape. They respondents believe that when these adolescents use these drugs, it would temporarily put their mind at ease. Same thing goes for relationship problems. However for the peer influence factor, that was frequently mentioned, underscores the influence of such a group on deviant behaviours. One of the reasons why peer influence has been perceived as an important factor during the stage of adolescence is perhaps due to its crucial role as an agent of socialization. Although, the peer group was previously regarded as second only to the parents in socializing the child, the peer group currently equals the family in terms of influence over adolescents (31). This according to this study, the increasing influence of peer group on adolescent behaviour could be because "adults and parents would not discuss certain sensitive issues, which the adolescents are curious about; adolescents are left to deal with these issues on their own. The 'most experienced' in the peer group usually takes the lead, gives advices and plays a parental role to other adolescents who are in desperate need of acceptance".

Now that we've known the factors that influence adolescent drug use as perceived by the public. It becomes imperative to know if they (public) think that availing them (adolescents) with information on the possible consequences of illicit drug use will curb their use of such drugs. However, more than half of the respondents (58.3\%) don't think that the knowledge of the possible consequences will necessarily stop the use of these drugs. Some of the reasons they have this perception is because, firstly, the instant gratification and euphoria that come with drug use might encourage adolescents to rationalize drug use. From their point of view, these adolescents believe that the fact drug use kill some persons does not mean it will kill everyone, in other words, consequences are over exaggerated. Secondly, there is the issue of habit. Changing habitual compulsive behaviours is difficulty and if drug use becomes a habitual for these adolescents, knowledge of the consequences later on wouldn't change anything in terms of usage. Other reasons are that the present feeling of pain, emptiness, trauma etc. cannot be compared to any later consequences and the peer group influence with social comparison i.e. adolescents taking up drug use in other to feel belonged or accepted among their peers. Looking at the However, more than half of the respondent believe that knowledge of the possible consequences can actually hinder these adolescents from using these drugs. The hypothesis tested shows that male respondents are more likely than female respondents to perceive that adolescents would consume illicit drugs even if

Page $13 / 17$ 
they knew the possible consequences. While planning interventions or programme for adolescents who use drugs, there should be an equal representation of both males and females as uniform representation will go a long way to guarantee and efficient programme development. Most of the strategic positions in our society (especially in communities) are headed by men and if information comes from mostly them, it could be misleading.

Furthermore, the study attempted to identify the categories of adolescents i.e. in - school (adolescents enrolled in a school) or out - of - school (adolescents not officially enrolled in any school) that are perceived (by the public) to be more involved in the use of drugs in Owerri metropolis. There is no significant difference in drug use between the two categories, however, the hypotheses tested in this regard shows that those with a higher level of education are more than likely to perceive a difference. Whileit is possible that the public believes that it does not matter the categories of adolescents (whether in or out-of-school, rural or urban area, male or female, etc.) when it comes to illicit drugs use, both categories are almost same, it also goes to show that respondents' level of education can and does influence their perception on the subject matter.

Finally, the study has helped to validate social learning theory. According to the theory, behaviour is influenced by environmental factors, not just psychological or cognitive factors. In the current study, we have found that peer influence, emotional problems, relationship problems, media, youthful exuberance, wanting to feel 'high' and other reasons are perceived factors that influence adolescents' use of illicit drugs. All of these factors represent either or all of the concepts developed in the social learning theory. For instance, while peer pressure could be representative of the environmental factors, emotional problems or youthful exuberance, and wanting to feel 'high' could be representative of the behavioural factors, psychological factors and how/what they expect to feel, respectively. We cannot talk about environmental factors without talking about the public and their perception of things. To address the increasing rate of illicit drug use, the public has a crucial role to play. Their perception of illicit drug use among adolescents must be ascertained. Understanding how the public perceives an issue may reveal the level of attention such an issue gets. To create and implement an efficient policy that will go a long way to address this public health issue, public perception is crucial. Ignoring public perception on issues that require modifying public policy or public behaviour, might result in the failure of technically good innovations (33). This theory can also serve as resource tools in the development of intervention strategies in tackling drug problems especially among adolescents.

\section{Study limitations}

The study only focused on the public's perception of factors that influence the drug use of adolescents. It however, did not discuss the public's perception on the consequences or the strategies to curbing this menace.

\section{Conclusion And Recommendation}

Peer influence, emotional problems, relationship problems, the influence of media (especially the social media), youthful exuberance, wanting to feel 'high' among several other identified reasons are perceived by the public as factors that influence adolescents' use of illicit drugs. More particularly, peer pressure was perceived by majority of the respondents as a major factor and it was also identified as rivaling the family in terms of influence.

In order to develop policies that will be more efficient in tackling the issue of drug use among adolescents, the understanding of the public on the subject matter needs to be ascertained. Therefore, through the public:

- A social environment should be created which would discourage drug use, with the community, schools and universities, educating children at a very early age (primary school level on the dangers of drug use and the value of life. 
- Finally, the communities, schools and universities should formulate policies to prevent drug use and should also hold seminars for parents and families to alert them early to the symptoms of drug use in their children.

\section{Abbreviations}

LGA: Local Government Area

N.C.E.: National Certificate Examination

O.N.D.: Ordinary National Diploma

H.N.D.: Higher National Diploma

RepOD: A representative of the office of the director

RepSW: A representative of the Social Welfare

\section{Declarations}

Ethic Approval and consent to participate

The study was approved by the ethics committee of the department of Sociology/Anthropology, University of Nigeria, Nsukka. Each participant was given a consent form to sign showing their consent to participate in the study.

\section{Consent for publication}

Not applicable.

Availability of data and materials

The datasets used and/or analyzed during the current study are available from the corresponding author on reasonable request.

Competing interest

The authors declare that there are no competing interests.

\section{Funding}

This study was personally funded by the lead author. There were no other sources of funding.

Authors' contribution

OUU conceived the topic and prepared the first draft. EN guided the creation of the topic and also reviewed and made strategic inputs to the paper, section by section until the final draft. AO reviewed and made strategic inputs to the paper. All authors read and approved the final manuscript

Acknowledgement

Not applicable. 
OUU has a M.Sc. in Medical Sociology from University of Nigeria, Nsukka. EN is a retired Professor from the department of Sociology/Anthropology, University of Nigeria, Nsukka. AO is a lecturer with the department of Sociology/Anthropology, University of Nigeria, Nsukka.

\section{References}

1. Deressa W, Azazh A. Substance use and its predictors among undergraduate medical students of Addis Ababa University in Ethiopia. BMC Public Health. 2011;11(1):660.

2. Gebreslassie M, Feleke A, Melese T. Psychoactive substances use and associated factors among Axum University students, Axum Town, North Ethiopia. BMC Public Health. 2013;13(1):693.

3. FMCPsych AOA, FMCPsych SS. ALCOHOL AND PSYCHOACTIVE SUBSTANCE USE AMONG MEDICAL STUDENTS OF THE UNIVERSITY OF ILORIN, NIGERIA.

4. Reddy P, Resnicow K, Omardien R, Kambaran N. Prevalence and correlates of substance use among high school students in South Africa and the United States. Am J Public Health. 2007;97(10):1859-64.

5. United Nations. World Drug Report 2013 UNITED NATIONS OFFICE ON DRUGS AND CRIME Vienna [Internet]. 2013 [cited 2020 May 26]. Available from: www.unodc.org

6. World Health Organization. Global Status Report on Alcohol and Health 2011 [Internet]. WHO. 2012 [cited 2018 May 26]. Available from: https://www.who.int/substance_abuse/publications/alcohol_2011/en/

7. World Health Organization. Atlas on substance use (2010): resources for the prevention and treatment of substance use disorders [Internet]. 2010 [cited 2019 May 26]. Available from: https://www.who.int/publicationsdetail/9789241500616

8. Kalsi H. Substance abuse amongst high school and college students. 2015;

9. Tshitangano TG, Tosin $\mathrm{OH}$. Substance use amongst secondary school students in a rural setting in South Africa: Prevalence and possible contributing factors. African J Prim Heal care Fam Med. 2016;8(2):1-6.

10. Resko SM. Public perceptions and attitudes toward adolescent marijuana use: Results of a statewide survey. Sage Open. 2014;4(1):2158244013518055.

11. Rey JM, Martin A, Krabman P. Is the party over? Cannabis and juvenile psychiatric disorder: the past 10 years. J Am Acad Child Adolesc Psychiatry. 2004;43(10):1194-205.

12. Asbridge M, Hayden JA, Cartwright JL. Acute cannabis consumption and motor vehicle collision risk: systematic review of observational studies and meta-analysis. Bmj. 2012;344:e536.

13. Hall W, Degenhardt L. Adverse health effects of non-medical cannabis use. Lancet. 2009;374(9698):1383-91.

14. Oluremi Fareo D. DRUG ABUSE AMONG NIGERIAN ADOLESCENTS STRATEGIES FOR COUNSELLING. J Int Soc Res. 2012;5(20).

15. Adegoke AA, Olasupo MO, Ayeni OB. Prevalence and pattern of male adolescents' substance abuse in Ibadan metropolis. Int J Soc Sci Educ. 2014;4(4):890-7.

16. Alhyas L, Al Ozaibi N, Elarabi H, El-Kashef A, Wanigaratne S, Almarzouqi A, et al. Adolescents' perception of substance use and factors influencing its use: a qualitative study in Abu Dhabi. Jrsm Open. 2015;6(2):2054270414567167.

17. Osman T, Victor C, Abdulmoneim A, Mohammed H, Abdalla F, Ahmed A, et al. Epidemiology of substance use among university students in Sudan. J Addict. 2016;2016.

18. Ndu FO, Ndu LO, Olarewaju AO, Somoye F. Basic Science: An Integrated Science Course for Junior Secondary School 1. Ikeja: Longman Nigeria Plc; 2009. 
19. Ndom RJE, Igbokwe DO, Ekeruo N. Students' Opinion on Substance Use, Violent Behavior and Possible Intervention Strategies in a Nigerian Public University. Eur Sci Journa. 2012;8(19):191-211.

20. Fatoye FO, Morakinyo O. Substance use among secondary school students in rural and urban communities in South Western Nigeria. East Afr Med J. 2002;79(6):299-305.

21. Shehu AU, Idris SH. Marijuana smoking among secondary school students in Zaria, Nigeria: Factors responsible and effects on academic performance. Ann Afr Med. 2008;7(4).

22. Adelekan ML, Ndom RJ. Trends in prevalence and pattern of substance use among secondary school pupils in Ilorin, Nigeria. West Afr J Med. 1997;16(3):157-64.

23. Chikere EIC, Mayowa MO. Prevalence and perceived health effect of alcohol use among male undergraduate students in Owerri, South-East Nigeria: a descriptive cross-sectional study. BMC Public Health. 2011;11(1):118.

24. Mamman H, Othman AT, Lian LH. Adolescent's and drugs abuse in Nigeria. J Biol Agric Healthc. 2014;4(1):5-9.

25. Abasiubong F, Udobang JA, Idung AU, Udoh SB, Jombo HE. A comparative study of pattern of substance use in two Nigerian cities located in the Southern and Northern Nigeria. African Res Rev. 2014;8(2):52-67.

26. Ibebuike JE, Nwokike IG, Iquiro AA, Ibebuike KE, Nwinyinya OP, Oti I. PREVALENCE OF SUBSTANCE ABUSE AMONG STUDENTS OF EZIACH SENIOR SECONDARY SCHOOL ORLU LOCAL GOVERNMENT AREA, IMO STATE. 2017;

27. Ilo Cl. Drug Use and Sources of Drug Information Among Secondary School Students in Imo State, Nigeria. Eur J Educ Sci. 2017;4(1):76-85.

28. Adebiyi AO, Faseru B, Sangowawa AO, Owoaje ET. Tobacco use amongst out of school adolescents in a Local Government Area in Nigeria. Subst Abuse Treat Prev Policy. 2010;5(1):24.

29. Severin WJ, Tankard JW. Communication theories: Origins, methods, and uses in the mass media. Longman New York; 1997.

30. Sadaf A. Public perception of media role. Int J Humanit Soc Sci. 2011;1(5):228-36.

31. Seun AV. The Effects of Drug Abuse among University Undergraduates in Nigeria (The Case of Federal University, Oye-Ekiti) [Internet]. Federal University, Oye-Ekiti; 2013. Available from:

https://www.academia.edu/17085799/The_effects_of_Drug_Abuse_among_University_undergraduates_in_Nigeria

32. Omigbodun 00, Babalola O. Psychosocial dynamics of psychoactive substance misuse among Nigerian adolescents. 2004;

33. Granger-Morgan M. Public perception, understanding, and values. Ind green game Implic Environ Des Manag Ed by Richards, DJ, Natl Acad Press Washingt DC. 1997;200-11.

\section{Supplementary Files}

This is a list of supplementary files associated with this preprint. Click to download.

- STROBEStatement.docx 